Annuaire du Collège de France 2017-2018

\title{
Javier Teixidor (1930-2017)
}

\section{Carlo Ossola}

\section{OpenEdition}

\section{Journals}

Édition électronique

URL : https://journals.openedition.org/annuaire-cdf/16634

DOI : 10.4000/annuaire-cdf.16634

ISBN : 978-2-7226-0572-5

ISSN : 2109-9227

Éditeur

Collège de France

Édition imprimée

Date de publication : 30 décembre 2020

Pagination : 741-744

ISBN : 978-2-7226-0516-9

ISSN : 0069-5580

\section{Référence électronique}

Carlo Ossola, « Javier Teixidor (1930-2017) », L'annuaire du Collège de France [En ligne], 118 | 2020, mis en ligne le 01 avril 2021, consulté le 22 août 2022. URL : http://journals.openedition.org/annuaire-cdf/ 16634 ; DOI : https://doi.org/10.4000/annuaire-cdf.16634 


\section{JAVIER TEIXIDOR (1930-2017)}

Javier Teixidor est né le 13 novembre 1930 à Barcelone. Après des études secondaires à Valence, il commence sa formation académique par des études de philosophie à l'université de Valence (de 1949 à 1953) et se dirige ensuite, dès 1955, vers l'étude des langues sémitiques (notamment l'hébreu, l'araméen et le syriaque) et l'histoire du Proche-Orient ancien, à l'Institut oriental de Rome. Il obtient sa thèse de doctorat en 1960.

Bien plus tard, lorsqu'il sera professeur honoraire du Collège de France, Javier Teixidor écrira un livre intitulé Mon père, l'Araméen errant ${ }^{1}$, dont le titre fait allusion à un texte du livre du Deutéronome. Mais il y a peut-être aussi une certaine allusion autobiographique, car les années suivant sa thèse furent marquées par une très forte mobilité et des séjours dans plusieurs pays et continents. De 1961 à 1962, il se forme à l'archéologie du Levant durant un séjour à l'École biblique de Jérusalem. Il devient ensuite boursier du gouvernement irakien, chargé de publier les textes araméens du musée de Bagdad. De 1963 à 1965, il travaille comme boursier de l'Unesco aux campagnes de fouilles de sauvetage de Wadi Halfa (au Soudan), puis à Bagdad, Mossoul et Hatra (Irak), ainsi qu'à Damas, Alep et Palmyre (Syrie). De 1965 à 1966, il est rattaché à l'Institut français d'archéologie de Beyrouth où il se consacre notamment aux fouilles de Palmyre. Après avoir passé une année au département des langues et des littératures du Proche-Orient ancien à Yale, il obtient un poste à la Columbia University de New York au département d'histoire, où il restera neuf ans (de 1967 à 1976). En 1977, il revient en France et entre au CNRS ; en 1991, il devient directeur de recherche de première classe et directeur de l'URA 1062 (Études sémitiques). Cette même année, il obtient la nationalité française et reçoit, en 1993, le prix Clermont-Ganneau de l'Académie des inscriptions et belles-lettres. Il est élu au Collège de France sur la chaire Antiquités sémitiques en 1995, chaire qu'il occupera jusqu'en 2001. Le $1^{\mathrm{er}}$ avril 1996, il donne sa leçon inaugurale qui ouvre son premier cours au Collège de France avec, comme intitulé, "Aristote en syriaque: les philosophes de la Haute-Mésopotamie au $\mathrm{VI}^{\mathrm{e}}$ siècle ». Cet intitulé reflète fort bien les deux centres d'intérêts de Javier Teixidor, la philosophie et les études ouest-sémitiques, notamment le syriaque. Dans sa leçon inaugurale, Javier Teixidor soulignait l'importance d'Aristote pour des philosophes de la Haute-Mésopotamie qui utilisaient ses œuvres traduites en

1. J. TEIXIDOR, Mon père, l'Araméen errant, Paris, Albin Michel, 2003. 
syriaque pour réfléchir dans et sur leur propre langue. Ces philosophes syriaques créèrent un courant de pensée où se rencontrent heureusement l'Orient ancien et la civilisation grecque. Javier Teixidor démontra dans ses premiers cours comment cette rencontre s'est poursuivie après l'émergence de l'Islam, et a trouvé son apogée au IX ${ }^{\mathrm{e}}$ siècle dans le cercle des intellectuels juifs, musulmans et chrétiens de la Bagdad des premiers califes abbassides. En 2003, Javier Teixidor publie un livre sur Paul le Perse, logicien $d u V^{e}$ siècle $^{2}$. En 2007, il rédigea son dernier livre sur ce sujet, intitulé Hommage à Bagdad: traducteurs et lettrés de l'époque abbasside ${ }^{3}$. Dans cet ouvrage, il traduit et commente les textes aristotéliciens écrits en langue syriaque par des auteurs vivant en Syrie du Nord et en Turquie orientale du $\mathrm{VI}^{\mathrm{e}}$ au $\mathrm{IX}^{\mathrm{e}}$ siècle. Ce travail est le résultat de trois cours au Collège de France. Il y décrit la capitale des Abbassides et ses écoles de traduction où œuvraient chrétiens, juifs et musulmans. Il y montre également le lien intrinsèque entre la réception d'Aristote, le sort des lettres arabes et persanes et la naissance de la culture islamique. Dans l'avant-propos, il écrit que la possibilité de se «remémorer la lointaine gloire impériale [1]'aide à exorciser le funeste tourbillon de violence et d'affliction d'aujourd'hui ».

Revenons aux contributions de Javier Teixidor, qui ont précédé cet opus majeur. Il est l'auteur d'une dizaine d'ouvrages dans lesquels alternent des publications consacrées à des documents littéraires inédits et des publications plus synthétiques. Ses textes publiés dans le Bulletin d'épigraphie sémitique (1964-1980) concernent des matériaux phéniciens provenant notamment de Byblos et de Sidon, des documents araméens et nabatéens ainsi que les textes en syriaque de la région du Moyen-Euphrate. Il a porté une attention toute particulière aux inscriptions de Palmyre. Cette collection de textes qui parurent d'abord dans le bulletin annuel d'épigraphie sémitique de la revue Syria et qui comporte plusieurs milliers d'inscriptions est devenue un ouvrage de base pour tous les épigraphistes et les historiens du Proche-Orient ancien. Javier Teixidor a également été l'instigateur d'un ouvrage collectif sur l'univers phénicien paru en $1989^{4}$ et qui a connu une deuxième édition en 1995. Ce livre a profondément marqué les recherches sur la civilisation phénicienne.

Javier Teixidor publia également des ouvrages d'histoire et d'histoire des religions. En 1977 parut The Pagan God. Popular Religion in the Greco-Roman Near East ${ }^{5}$, ouvrage dans lequel il chercha à démontrer que les inscriptions phéniciennes et araméennes du premier millénaire avant l'ère chrétienne font apparaître une tendance monolâtrique qui a facilité l'émergence du monothéisme. Il observe que, dans chaque centre cultuel important, on rencontre un dieu qui de fait concentre sur lui l'activité cultuelle du temple en question. Les sociétés sémitiques nomades ou semi-nomades du premier millénaire sont, selon Javier Teixidor, quasi monothéistes, non à la suite de raisonnements théologiques visant à contester

2. J. TeIXIDOR, Aristote en syriaque. Paul le Perse, logicien $d u v I^{e}$ siècle, Paris, CNRS Éditions, 2003.

3. J. Teixidor, Hommage à Bagdad: traducteurs et lettrés de l'époque abbasside, Paris, CNRS Éditions, 2007.

4. M. Gras, P. Rouillard et J. TeIXIDOR, L’Univers phénicien, Paris, Arthaud, 1989.

5. J. TeIXIDOR, The Pagan God. Popular Religion in the Greco-Roman Near East, Princeton, Princeton University Press, 1977. 
l'existence d'autres dieux, mais par la nécessité même de l'appartenance tribale. Javier Teixidor démontre également qu'il n'y eut guère de changements quant à la religion populaire du Levant à l'époque hellénistique, les cultes à mystères étant réservés à une élite fortement hellénisée.

Palmyre a été une préoccupation majeure dans le travail scientifique de Javier Teixidor. En 1979, il publie The Pantheon of Palmyra ${ }^{6}$ qui peut se lire comme un complément au travail que nous venons d'évoquer. Dans ce livre, dédié aux cultes de Palmyre, il décrit les différentes divinités à l'aide des inscriptions et démontre que les différentes tribus qui se sont installées autour de l'oasis préservent leurs panthéons tribaux. Il n'existe donc pas de panthéon «national » palmyrénien. L'installation du culte de Bel (Baal) à Palmyre fut une création des prêtres du temple dans le but d'unifier la vie religieuse et politique de la ville. Dans une publication de 1984, Teixidor s'est également intéressé au rôle économique de Palmyre. Vouée au trafic caravanier, Palmyre était constamment en contact avec des tribus seminomades auxquelles elle achetait des chameaux et confiait ses troupeaux. C'est l'abondance des citernes qui a permis le développement d'une riche agriculture et qui a favorisé la fixation des tribus et leur union politique autour de l'oasis. Javier Teixidor a également contribué à la mise en valeur du patrimoine palmyrénien au Louvre en éditant, en 1993, un catalogue sur tous les objets de Palmyre conservés dans le musée.

C'est deux ans après la fin de sa carrière au Collège de France (2001), qu'il publie, en plus des ouvrages sur les aristotéliciens syriaques, l'ouvrage déjà mentionné : Mon père, l'Araméen errant. Commentaire libre d'un texte biblique fameux, également le résultat d'un cours au Collège de France. Il y révèle ses compétences bibliques et ses connaissances des débats autour de la formation du Pentateuque. Partant de la citation du chapitre 26 du livre du Deutéronome, Javier Teixidor montre qu'il y a dans ce texte un raccourci frappant de l'histoire des Hébreux qui opère la combinaison de l'épopée des Patriarches et de celle de l'Exode. Ce texte ne remonte pas à une époque archaïque mais nous fait comprendre de quelle manière les intellectuels juifs du Second Temple se sont représenté le parcours suivi par une population araméenne qui allait devenir le peuple juif après l'Exil. Ce n'est qu'à ce moment, aux alentours du $\mathrm{IV}^{\mathrm{e}}$ siècle avant notre ère, qu'apparaît la nouvelle communauté religieuse, le judaïsme, qui allait marquer l'histoire de l'Occident. En 2006, Javier Teixidor publie un livre intitulé Le Judéo-christianisme, destiné à un large public. Malgré son titre, l'ouvrage ne porte pas sur les communautés chrétiennes continuant à respecter la Loi juive, mais sur les relations entre juifs et chrétiens et, à travers elles, sur l'antisémitisme. Pour l'auteur, les religions juive et chrétienne, judaïsme et christianisme, sont organiquement différentes l'une de l'autre, et le dialogue entre elles est intrinsèquement impossible. Si les chrétiens parlent de judéo-christianisme, c'est « afin de soulager leur conscience vis-à-vis des crimes commis en Europe ${ }^{7}$ ». La démonstration recourt à des sources de toutes les époques, avec une prédominance de la période moderne.

Cet intérêt pour le judaïsme se renforce durant les dernières années de son activité intellectuelle. Javier Teixidor mène alors des recherches sur le philosophe Spinoza, notamment sur son affirmation d'une dichotomie entre la foi et la raison et sur son

6. J. TEIXIDOR, The Pantheon of Palmyra, Leyde, Brill, 1997.

7. J. TEIXIDOR, Le Judéo-christianisme, Paris, Gallimard, 2006, p. 166. 
idée selon laquelle les pratiques religieuses des anciens Sémites n'étaient nullement régies par des réflexions d'ordre philosophique. J'ai pu discuter de ce manuscrit à plusieurs reprises avec Javier Teixidor, mais malheureusement son état de santé ne lui a pas permis de le terminer. Il nous a quittés le 20 septembre 2017 et a marqué les études sémitiques d'une manière profonde.

Pr Carlo Ossola, 25 mars 2018 